Advances in Geosciences, 5, 13-17, 2005

SRef-ID: $1680-7359 /$ adgeo/2005-5-13

European Geosciences Union

(c) 2005 Author(s). This work is licensed

under a Creative Commons License.

\title{
Integrated analysis of water quality in a mesoscale lowland basin
}

\author{
A. Habeck, V. Krysanova, and F. Hattermann \\ Potsdam Institute for Climate Impact Research (PIK), Telegrafenberg, 14473 Potsdam, Germany \\ Received: 7 January 2005 - Revised: 1 August 2005 - Accepted: 1 September 2005 - Published: 16 December 2005
}

\begin{abstract}
This article describes a modelling study on nitrogen transport from diffuse sources in the Nuthe catchment, representing a typical lowland region in the north-eastern Germany. Building on a hydrological validation performed in advance using the ecohydrological model SWIM, the nitrogen flows were simulated over a 20 -year period (19812000). The relatively good quality of the input data, particularly for the years from 1993 to 2000, enabled the nitrogen flows to be reproduced sufficiently well, although modelling nutrient flows is always associated with a great deal of uncertainty. Subsequently, scenario calculations were carried out in order to investigate how nitrogen transport from the catchment could be further reduced. The selected scenario results with the greatest reduction of nitrogen washoff will briefly be presented in the paper.
\end{abstract}

\section{Introduction}

The work presented here was carried out as a part of the consortium project "Bewirtschaftungsmöglichkeiten im Einzugsgebiet der Havel" ("Potential for water resources management in the Havel River Basin"), whose major objective was to accompany scientifically the practical application of the Water Framework Directive in Germany. According to this, the surface water of the Havel River (see Fig. 1), which is one of the largest tributaries of the Elbe River, should be brought into a "good ecological condition" by the year 2015 . The main aim of the project work was to suggest management options leading to reduction of nitrogen and phosphorous transport from diffuse sources to the Havel river system. For this purpose, the nutrient transport from diffuse sources represented mainly by agriculture, was simulated using the ecohydrological model SWIM (Krysanova et al., 2000), and a number of land use change scenarios were applied to investigate their effect on reduction of nutrient load.

Correspondence to: A. Habeck

(habeck@ pik-potsdam.de)

\section{The Model SWIM}

SWIM (Soil and Water Integrated Model, Krysanova et al., 1998) is a continuous-time, spatially distributed ecohydrological model for mesoscale and large river basins. It works on a daily time step and integrates hydrology, vegetation, nutrients (carbon, nitrogen and phosphorus) and sediment fluxes at the river basin scale. The spatial aggregation units for river basin modelling are subbasins, which are further disaggregated into hydrotopes - hydrologically homogenous areas within subbasins. The hydrotopes are delineated by overlaying of subbasin, land use and soil maps (Krysanova et al., 2000). The model is connected to meteorological, land use, soil, vegetation and agricultural management input data.

Water fluxes, plant growth and nitrogen dynamics are calculated with the daily time step for every hydrotope. The nitrogen module includes the following pools: nitrate nitrogen, active and stable organic nitrogen, organic nitrogen in the plant residue, and the flows: fertilisation, input with precipitation, mineralisation, denitrification, plant uptake, wash-off with surface and subsurface flows, leaching to ground water, and loss with erosion. The lateral water and nutrient fluxes are routed over the river network, taking transmission losses into account.

For detailed process descriptions, validation studies and data see Krysanova et al. (1998, 1999, 2000). An extensive multiscale and multicriterial validation of the model in the German part of the Elbe basin and its subbasins including sensitivity and uncertainty analyses is described in Hattermann et al. (2004).

\section{Case study area}

The Nuthe catchment (drainage area about $1800 \mathrm{~km}^{2}$, see Fig. 1) is a typical catchment within the Havel River basin located in the north-eastern German lowland. The drainage area is characterised by a mean annual precipitation of about $560 \mathrm{~mm}$ and a mean annual temperature of $9.1^{\circ} \mathrm{C}$. In 


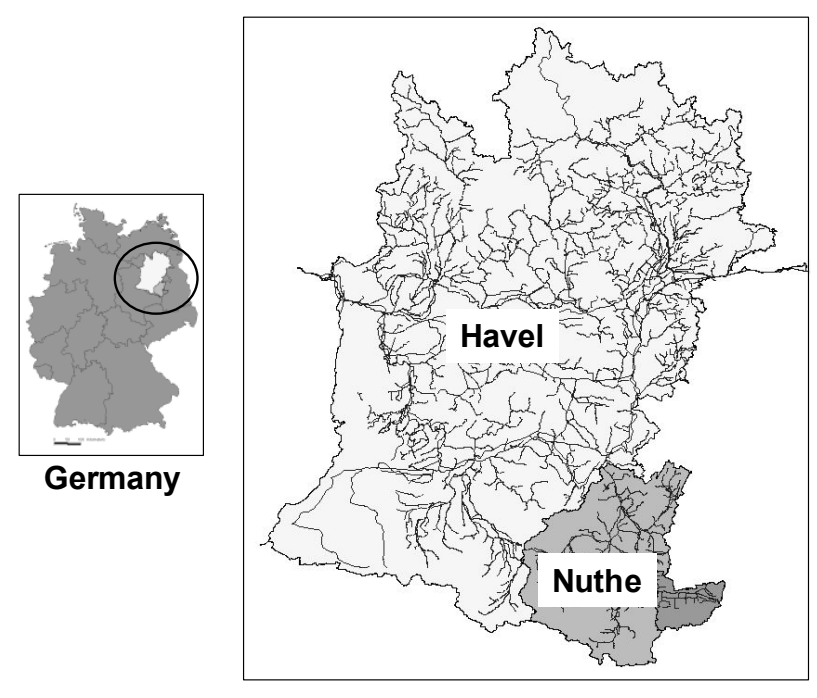

Fig. 1. The location of the Havel and Nuthe catchments.

hydrological terms, the catchment area is characterized by almost semi-arid conditions: usually in summer there is a lack of precipitation, but in winter a surplus. The drainage behaviour of the Nuthe is regulated by reservoir and ditch systems. Soils are predominantly formed during the last ice age, over loose bedrocks, which are often influenced by shallow groundwater. Typical soil types are brown soils (Braunerde), gley-podsols, gleys and organic fen soils. The large part of the Nuthe catchment $(47 \%)$ is used for agriculture, but there is also a large proportion of forest $(42 \%)$. While at the end of the 1980s the Nuthe was considered as strongly polluted, today it is one of the rivers in Germany with the lowest nitrate pollution because of the notable reduction of nutrient emissions from different sources during the last 15 years (see also Sect. 5 for details).

\section{Modelling results}

In order to fulfil the basic requirement for the water quality modelling of a catchment, the model SWIM was first hydrologically validated for the Nuthe. The comparison of the measured and simulated water discharge was satisfactory: the daily Nash and Sutcliffe efficiency for the validation period 1981-1987 was 0.57 , and the mean long term difference between the observed and simulated river discharge at the basin outlet was $+4 \%$. This is acceptable for the lowland basin, especially if one takes into account that the hydrological modelling is more complicated in an anthropogenically influenced lowland catchment due to the specific local hydrological conditions such as influence of shallow groundwater, artificial reservoirs and drainage systems.

After the hydrological validation, the simulation of the nitrate cycling in soil and transport to the river system was performed, and the results were compared with available data of observation. In order to preliminarily check the balance of nitrogen in soil simulated by the model, SWIM was first applied in the framework of the workshop "Modelling Water and Nutrient Dynamics in Soil Crop Systems" organised by the Leibniz-Centre for Agricultural Landscape and Land Use Research (ZALF). The objective was to perform a pointscale validation at several sites in Germany, which included one site in the Havel catchment. The model was able to reproduce the observed nitrogen cycling in soils (nitrate- $\mathrm{N}$ content in different soil layers) quite well. A detailed description of the study and results can be found in Post et al. (2004) ${ }^{1}$.

After that nitrogen validation for the Nuthe catchment was performed. The vertical transformation processes in soil profile as well as the retention and denitrification processes in the catchment during the lateral transport were taken into consideration. Both point and diffuse sources of pollution were considered, though exact information about crop rotations and fertiliser application (amounts and timing) was missing and had to be substituted by general or expert knowledge for the region. The comparison of the simulated daily values for nitrate concentration with the measured ones in the Nuthe for the years from 1993 to 2000 shows a satisfactory result, despite of some differences in 1997 and 1999 (Fig. 2), which could be caused by imprecise input information mentioned above.

The example of the Nuthe also demonstrates that nutrient modelling is usually associated with some uncertainty caused by different reasons. Thus it is important, for example, that the model is subject to a comprehensive hydrological validation in advance, since errors in the calculation of water discharge have a notable influence on the results of the nutrient dynamics modelling. Moreover, data on land use and land management, such as crop rotations and timing and quantities of fertiliser application, need to be known in order to correctly represent the nutrient balance in soil. Therefore, the influence of different fertilisation practices was investigated additionally in our study.

One such example is shown in Fig. 3, which presents the sensitivity of the model to the amount of applied mineral nitrogen fertilisers considering the reference case along with increasing/decreasing the amount of nitrogen fertiliser by $40 \%$. One can see that the amount of nitrogen application in soil particularly affects the peak concentrations in river. This confirms in turn that the precise adjustment of fertiliser quantities should not be ignored. Further, the parameters for nutrient retention and nutrient denitrification during the lateral transport should be plausibly chosen and should be appropriate for the region, since both factors have a notable influence on the simulation results.

In the next step the long-term dynamics of the nitrate $\mathrm{N}$ concentration in the Nuthe River was analysed for the period 1982-2000 (Fig. 4). The measured data show that since the middle of the 1980s, the level of nitrate $\mathrm{N}$ concentration in

\footnotetext{
${ }^{1}$ Post, J., Habeck, A., Hattermann, F., Krysanova, V., Wechsung, F., and Suckow, F.: Evaluation of water and nutrient dynamics in soil-crop systems using the eco-hydrological catchment model SWIM (Soil and Water Integrated Model), Nutrient Cycling in Agroecosystems, submitted, 2004.
} 
(a)

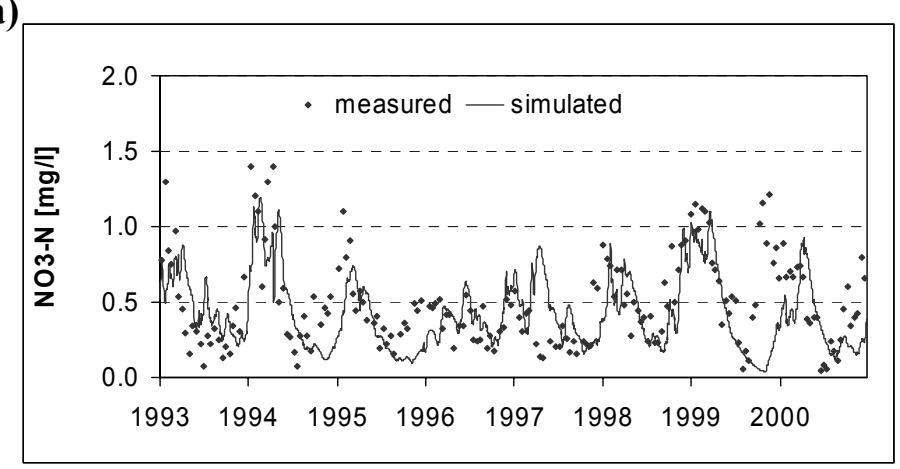

(b)

\section{Standard deviation \\ measured: 0.28 \\ simulated: 0.25 \\ Longterm Average}

measured: 0.45

simulated: 0.49

Fig. 2. (a) Comparison of the simulated daily values for nitrate $\mathrm{N}$ concentration with the measured ones (one measurement in two weeks) in the Nuthe, gauge Potsdam / Babelsberg (1993-2000); (b) Standard deviation and long-term average values for the time period 1993-2000.

the Nuthe River has declined considerably. The reasons for this can be found in changes in nutrient emissions. Generally three different sources of nitrogen pollution were identified for the Nuthe catchment area in the 1980s:

1. point sources (public sewage treatment plants and direct input from industrial sources),

2. diffuse sources (manly input from agriculture fields and the atmosphere), and

3. sewage fields (disposal of communal sewage on ground) (Werner et al., 1994).

Until the mid-1980s about 45 million $\mathrm{m}^{3}$ of sewage per year were being piped to the sewage fields in the Nuthe catchment. Sewage water was brought onto the fields not only during the vegetation period, but continuously. Due to the fact that the sewage fields covered only about $1 \%$ of the total Nuthe catchment area, and very large amounts of wastes were spread over the fields practically permanently, leading to the permanent wash-off from the highly polluted area, the sewage fields operated rather as a permanent point source polluter for the Nuthe basin (higher load accompanying lower discharge). Therefore it makes sense to consider this pollution source separately.

The analysis shows that the reduction of nitrogen concentration in the Nuthe River happened predominantly due to essential reduction of inputs from two sources: the sewage fields and diffuse sources. Since the beginning of the 1990s the volume of sewage on the sewage fields was significantly reduced, and in 1994 this method was completely discontinued (Tröger et al., 1995; Scheytt et al., 2000). Furthermore, from the early 1990s the use of industrial and mineral fertilizers on arable land in the basin was considerably reduced because of changes in agriculture management practices (fertilisation in accordance with plant requirements) (Behrendt et al., 2002).

In our modelling for 1982-2000 (see Fig. 4a) it was therefore taken into account that in the 1980s the input of nitrogen from point and diffuse sources was considerably higher than in the 1990s. Because exact input data on a daily or

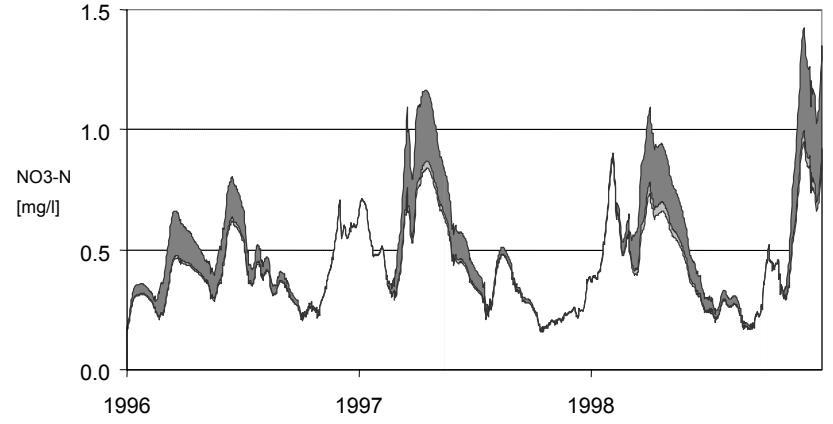

Fig. 3. Effect of different amounts of mineral nitrogen fertilisers on the daily nitrate concentration in the Nuthe for the time period 1996-1998. Middle line shows the reference case with $100 \mathrm{~kg} \mathrm{~N} /($ ha*a), and the dark/light grey shadowed areas indicate cases with increased/decreased amounts of fertilisers by $40 \%$.

monthly basis were lacking, the daily nitrogen input from the sources listed above was estimated using existing annual values. Therefore, the intraseasonal dynamics in the $1980 \mathrm{~s}$ could not be satisfactory reproduced. On the other hand, when the measured and the simulated monthly nitrate concentrations are compared (Fig. 4b), the change in the seasonal dynamics can be clearly seen. While the peak concentrations in the 1980s occurred during the summer months, in the 1990s they occurred in winter, which means that point source pollution prevailed in the 1980s, and diffuse source pollution prevailed in the 1990s. The closure of sewage fields along with other measures mentioned above definitively led to the observed significant reduction in $\mathrm{N}$ concentrations, and to the change in seasonal dynamics. This conclusion was confirmed by the simulation experiment with SWIM (Fig. 4).

\section{Scenario calculations}

Building on the model simulation of basic conditions between the years 1988 and 2000, a number of land use/land management scenarios were applied to find the way of further reduction of diffuse source pollution in the Nuthe River. 
(a)

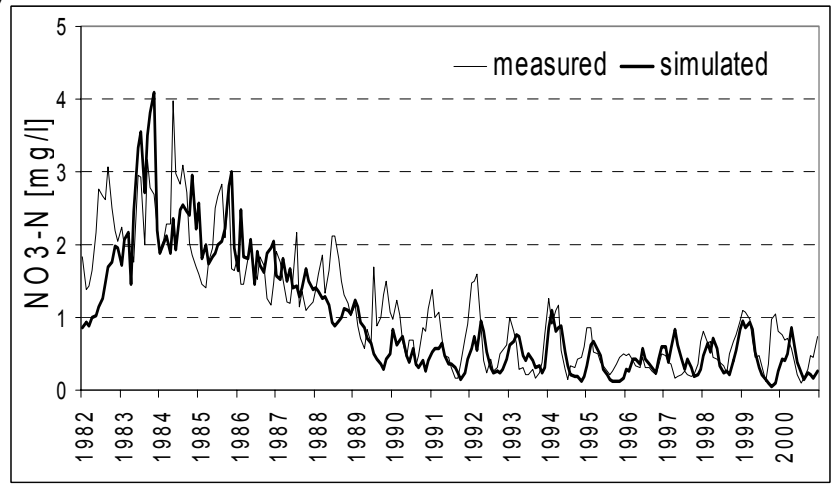

(b)

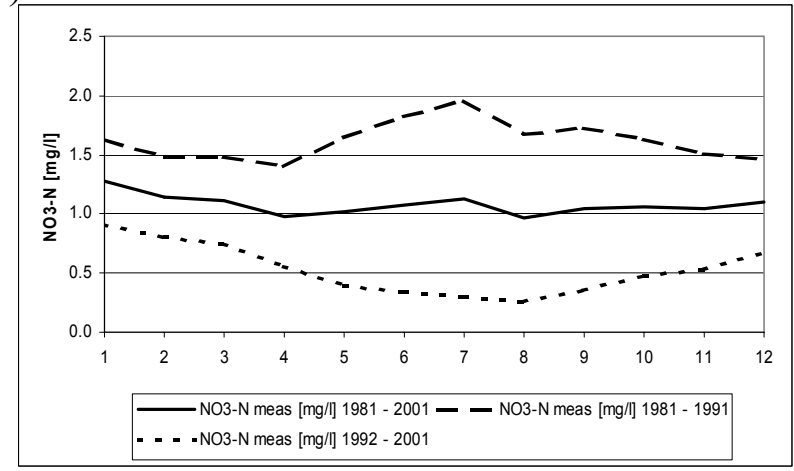

Fig. 4. (a) Comparison of the simulated monthly values for nitrate concentration with the measured ones in the Nuthe from 1982 until 2000 (b) Monthly long-term average values of the measured nitrate concentration for three time periods.

Table 1. Proportion of land use types in the Nuthe catchment for the time periods $1988-2000$ (reference case) and $2003-2015$ (scenario)

\begin{tabular}{ccc}
\hline Land Use Type & 1988-2000 [\%] & 2003-2015 [\%] \\
\hline Agriculture & 47 & 36 \\
Forest & 42 & 43 \\
Others & 10 & 22 \\
\hline
\end{tabular}

Table 2. Emissions of nitrogen from diffuse sources in the Nuthe catchment for the time periods 1988-2000 (reference case) and 2003-2015 (scenario) (a) total emissions in [kt/a] (b) emissions weighted according to the area in $[\mathrm{kg} / \mathrm{ha} * \mathrm{a}]$.

(a)

\begin{tabular}{ccc}
\hline Land Use Type & 1988-2000 [kt/a] & 2003-2015 [kt/a] \\
\hline Total & 3.9 & 2.6 \\
\hline Agriculture & 2.3 & 1.2 \\
Forest & 0.8 & 0.1 \\
Others & 0.8 & 1.2 \\
\hline
\end{tabular}

(b)

\begin{tabular}{ccc}
\hline Land Use Type & $1988-2000[\mathrm{~kg} / \mathrm{ha} * \mathrm{a}]$ & $2003-2015[\mathrm{~kg} / \mathrm{ha} * \mathrm{a}]$ \\
\hline Total & 23 & 15 \\
\hline Agriculture & 31 & 21 \\
Forest & 11 & 2 \\
Others & 41 & 31
\end{tabular}

The scenarios were produced by the working group in the Havel consortium project (Jacobs et al., 2003). Here results for one scenario described in Table 1, which relates to the years 2003 to 2015 and assumes significant reduction of arable land and its conversion to set-aside areas and wetlands, are presented.
According to this scenario, arable land is reduced from $47 \%$ to $36 \%$. In particular the areas used for intensive agriculture and pasture decline. The share of land used for extensive pasture and set-aside, on the other hand, increases. The main reason for the increase of "other types of land use" is the extension of wetlands not used for agriculture from $1 \%$ to $12 \%$. Although the overall share covered by forest remains fairly constant according to Table 1 , there are considerable changes. The older stands of deciduous, coniferous and mixed woodlands have been reduced in favour of young stands. Though the areas for different types of land use in this scenario changed, the fertiliser quantities and timing, crop rotations and the climatic boundary conditions were kept constant.

The objective was to study how and to what extent changes in land use may reduce the nitrogen discharge from diffuse sources. Table 2 shows that this can be achieved with the planned changes in land use. In total the amount of nitrogen from diffuse sources sinks from 3.9 to $2.6 \mathrm{kt} / \mathrm{a}$. Also the nitrogen emissions weighted according to area are reduced from 23 to $15 \mathrm{~kg} / \mathrm{ha}^{*} \mathrm{a}$. This corresponds to reductions of $33 \%$ and $35 \%$ respectively. If one looks more closely at the three different groups of land use, it can be seen that expectations have been fulfilled both for agriculture and forestry. For the other classes of land use, particularly the wetlands not used for agriculture purposes, there was an increase in nitrogen discharge, which is due to the fact that the area for this land use was considerably increased. The volume of discharge weighted according to area, however, shows the expected decrease in nitrogen discharge (Table $2 b$ ).

\section{Outlook}

The scenario calculations make it clear that simply by changes in land use, a significant reduction of nitrogen transport to surface waters can be achieved. The next step would be to examine the effect of changes in fertiliser quantities and timing, cropping patterns or climatic conditions. The 
method could be transferred to other catchments, where water quality is a problem and reduction of agricultural diffuse pollution is required.

Edited by: P. Krause, K. Bongartz, and W.-A. Flügel

Reviewed by: anonymous referees

\section{References}

Behrendt, H., Opitz, D., and Schmoll, O.: Stoffeinträge in die Gewässer des Landes Brandenburg, Fachbeiträge des Landesumweltamtes, H. 68, Hrsg. Landesumweltamt Brandenburg, 2002.

Jacobs, J. and Jessel, B.: Entwicklung von Landschaftsszenarien als Grundlage für das Management von Flusseinzugsgebieten, UVPReport, H. 2/2003.

Hattermann, F. F., Wattenbach, M., Krysanova, V., and Wechsung, F.: Runoff simulations on the macroscale with the ecohydrological model SWIM in the Elbe catchment - validation and uncertainty analysis, Hydrological Processes, 19, 693-714, 2005.
Krysanova, V., Müller-Wohlfeil, D.-I., and Becker, A.: Development and test of a spatially distributed hydrological/water quality model for mesoscale watersheds, Ecological Modelling, 106, 263-289, 1998.

Krysanova, V. and Becker, A.: Integrated modelling of hydrological processes and nutrient dynamics at the river basin scale, Hydrobiologia, 410, 131-138, 1999.

Krysanova, V., Wechsung, F., Arnold, J., Srinivasan, R., and Williams, J.: SWIM, User manual, PIK-Report, H. 69, Potsdam Institut für Klimafolgenforschung, 2000.

Scheytt, T. and Grams, S.: Grundwasserströmung und beschaffenheit unter dem Einfluss 100-jähriger Rieselfeldwirtschaft, Wasser und Boden, 52, 15-22, 2000.

Werner, W. and Wodsack, H. P.: Stickstoff- und Phosphoreintrag in Fließgewässer Deutschlands unter besonderer Berücksichtigung des Eintragsgeschehens im Lockersteinbereich der ehemaligen DDR, Agrarspectrum, 88-122, 1994.

WRRL - Richtlinie 2000/.../EG des Europäischen Parlaments und des Rates zur Schaffung eines Ordnungsrahmens für Maßnahmen der Gemeinschaft im Bereich der Wasserpolitik, 2000. 